Lisbona, Luis.

Personal Investigador Predoctoral, Universitat Politècnica de València, Departamento de Escultura, Laboratorio de Luz.

\title{
Préstamos, apropiaciones y plagios. Meditaciones sobre los arquetipos de la web 2.0.
}

\section{Loans, appropiations and plagiarism. Meditations about the archetypes of the Web 2.0.}

\author{
TIPO DE TRABAJO:
}

Comunicación.

PALABRAS CLAVE:

Web 2.0, apropiación, comunidades virtuales, prosumer.

KEY WORDS:

Web 2.0, appropriation, virtual communities, prosumer.

\section{RESUMEN.}

En el último decenio hemos asistido a un cambio de paradigma en cuanto a la estructura y cohesión de nuestra vida diaria, la cual ha pasado a articularse mediante la implementación de una amplia gama de tecnologías relacionadas con la red, y que tienen un alcance global. Una de las características destacables de este nuevo paradigma es la aparición de una nueva tipología de usuario caracterizado por aunar los roles de productor y consumidor. Esto ha generado una web construida por los propios usuarios mediante el potencial creativo de las comunidades online. Sin embargo chasta que punto no estamos siguiendo los patrones establecidos por la web 2.0 y hasta qué punto pueden los usuarios replantear estas mecánicas dentro de estos espacios? Mi interés parte del propio papel de la práctica artística como elemento de reflexión sobre el funcionamiento de la red en base a la producción amateur realizada por diferentes subculturas y comunidades virtuales, poniendo en entredicho el concepto de originalidad. Términos como collage o pastiche han dado paso a sus nuevos y prolíficos equivalentes virtuales, pasando a formar parte de las prácticas apropiacionistas ya desarrolladas ampliamente durante el S.XX. En cambio aún no estaban adscritas a un medio tan enormemente saturado por la producción amateur. Este hecho ha posicionado más que nunca al artista como un antropólogo social que conecta y recicla diferentes materiales para reflexionar sobre el funcionamiento de este medio.

\section{ABSTRACT.}

In the last decades we have attended to a paradigm shift regarding to the structure and cohesion of our daily life, which has become articulated through the implementation of a wide range of technologies related to the network, and which have a global significance. One of the outstanding characteristics of this new paradigm is the appearance of a new typology of user characterized by his/her combination of the roles of producer and consumer. This has generated a web built by the users themselves through the creative potential of online communities. However, to what extent are we aren't following the standards established by Web 2.0 and to what extent can users rethink these mechanics within these spaces? My interest comes from the very role of artistic practice as an element of reflection on the operation of the network based on the amateur production carried out by different subcultures and virtual communities, questioning the concept of originality. Terms like collage or pastiche have given way to their new and prolific virtual equivalents, becoming part of the appropriationist practices already developed extensively during the S.XX. On the other hand, they were not yet ascribed to 
an environment so enormously saturated by amateur production. This fact has more than ever positioned the artist as a social anthropologist who connects and recycles different materials to reflect on the operation of this medium.

\section{CONTENIDO.}

\section{INTRODUCCIÓN.}

Tras las llegada de la Web 2.0 a mediados de la pasada década las barreras entre lo público y lo privado se volvieron más permeables que nunca, modificando sustancialmente nuestra visibilidad dentro de los media. Todas estas transformaciones han generado una tensión entre lo local y lo global alterando la relación entre sociedad, economía e Internet. Este cambio en las lógicas de Internet tiene su origen en el concepto propio de Web 2.0, acuñado por Darcy DiNucci ${ }^{1}$ y difundido por Tim O’Reilly ${ }^{2}$. Este surge en torno a las características novedosas de diferentes aplicaciones web surgidas tras la burbuja de las punto com, las cuales ejemplifican el cambio de la industria del software a los servicios actuales ofrecidos por la web, sustituyendo las licencias de usuario por el propio uso, transformando las aplicaciones en bases de datos especializadas. Esto nos ha convertido en individuos disueltos en los datos que producimos y a la vez conformados por estos datos. Estos datos han pasado a alimentar nuestras propias prótesis tecnológicas en forma de smartphones y wereables, planteando tal, y como Paul Virilio nos anunciaba en su obra Estética de la desaparición, la evanescencia del mundo material ante la hegemonía del virtual. De hecho, una de las principales formas de vigilancia es la acumulación de grandes cantidades de datos mediante diferentes estrategias de recolección ${ }^{3}$.

Como ya en 1970 Marshall McLuhan y Barrington Nevitt nos anunciaban en su libro Take Today ${ }^{4}$, el avance de la tecnología ofrece herramientas mediáticas de producción al alcance del público en general. Manuel Castells en su obra La Galaxia Internet nos habla, ya en 2001 sobre los nuevos consumidores-usuarios ${ }^{5}$ como: "aquellos receptores de aplicaciones y sistemas que no interactúan directamente con el desarrollo de Internet (aunque sus usos tienen un efecto agregado en la evolución del sistema)" ${ }^{\prime \prime}$. Como contrapunto a estos consumidores-usuarios Castells nos presenta a los productores-usuarios como los verdaderos productores primeros de Internet y de su cultura, compuesta por un conjunto de valores y creencias que componen su comportamiento en Internet, y que se conformó como la cultura hacker ${ }^{7}$. Por lo tanto cabría preguntarse

¿cómo podemos traducir o reinterpretar estas dinámicas y replantear los modelos participativos y de vigilancia que la web 2.0 plantea?

\section{DESARROLLO.}

Como hemos comentado, la comercialización de Internet en los años 90 y la cultura emprendedora de principios de siglo han producido un giro en la configuración y el modelo de negocio alrededor de Internet ${ }^{8}$. Con la llegada de la Web 2.0 el propio espacio de Internet es la plataforma en la cual se ubican diferentes tipos de blogs, redes sociales y otros tipos de web dinámicas que se nutren del contenido generado por los usuarios. Esto queda ubicado dentro de un sistema que se reinventa constantemente para adaptarse a las dinámicas de estos. Uno de los efectos del uso de estas herramientas por el gran público ha sido una tremenda sobreproducción de todo tipo de material en cualquier ámbito creativo nunca antes vista en otro periodo histórico. Esta sobreproducción es especialmente notoria en lo que se refiere a las tecnologías asociadas con nuestra vida diaria y la manera en la cual narramos nuestra propia existencia en imágenes y texto, pero también se hace extensiva a otros ámbitos relacionados con la creatividad, lo viral, las referencias culturales y las comunidades virtuales. Por tanto la reelaboración y apropiación de diferentes materiales en la red se ha convertido en una práctica muy extendida y acorde con las propias lógicas del "copy and paste" que los medios informáticos propician.

\footnotetext{
${ }^{1}$ DiNucci, Darcy, Fragmented future, 1999, [Consulta 23 de Enero de 2017] disponible en <http://darcyd.com/fragmented_future.pdf> 2 O'Reilly, Tim, What Is Web 2.0. Design Patterns and Business Models for the Next Generation of Software, 2005,

[Consulta 23 de Enero de 2017] disponible en <http://www.oreilly.com/pub/a/web2/archive/what-is-web-20.html>

3 Jansson, André, Christensen, Miyase, Media, surveillance and identity, Peter Lang, Nueva York, 2014, pag. 32.

${ }^{4}$ McLuhan, Marshall, Understanding Media, Mit Press, Cambridge, 1994, 145.

${ }^{5}$ Aunque quizás sería más preciso hablar de constructores o productores de este espacios y tecnologías ya que en la actualidad la producción de contenidos ha pasado a formar parte de la actividad de los usuarios online. En cambio estos primeros usuarios de la red retroalimentaban este sistema tecnológico propiciando su desarrollo en base a sus valores de código abierto y colaboración. De hecho la distribución libre del código fuente fue la base del desarrollo tecnológico de Internet

${ }^{6}$ Castells, Manuel. La Galaxia Internet, Areté, Barcelona, 2001, pag. 51.

${ }^{7}$ Himanen, Pekka, La ética hacker y el espíritu de la era de la información, Editorial Destino, 2002.

${ }^{8}$ No hay que olvidar como indica Castells que los protocolos TCP/IP, el sistema operativo UNIX y sus protocolos UUCP, los protocolos modem y los programas de la World Wide Web, entre otros, fueron distribuidos mediante software open source. Todas estas tecnologías fueron indispensables para el desarrollo de Internet tal y como lo conocemos hoy en día, por otro lado el trabajo de la comunidad fue clave para su implementación y mejora constante.
} 
Las referencias históricas a la apropiación, el préstamo y el plagio dentro del ámbito creativo son interminables. Sin embargo, la obra de Walter Benjamin El Libro de los Pasajes ${ }^{9}$ realizada entre 1927 y 1940, se muestra como una temprana forma radical de apropiación y citación, al componerse casi en su totalidad de multitud de citas de otros autores que mediante el montaje que el autor realiza adquieren sentido. Los ready made duchampianos o las obras de Joseph Cornell, entre otros, generan una inercia que muchos artistas continuaran a lo largo del siglo XX. Artistas como Richard Prince o Sherrie Levine ya en los 70 usan el apropiacionismo como parte central de su obra. Por otro lado el término pastiche nos habla, como nos cuenta William J. T. Mitchell ${ }^{10}$, de la multiplicidad dentro de la misma obra mediante una mezcla de diferentes estilos. Esta noción fue ampliamente reelaborada por el crítico de arte y teórico literario estadounidense Fredric Jameson en su obra La Posmodernidad o la lógica cultural del capitalismo avanzado ${ }^{11}$. Podríamos decir que tenemos un “lenguaje sobre lenguajes"12, por lo tanto cuando hablamos de las diferentes estrategias apropiacionistas, estaríamos hablando de una reubicación textual de una obra. La posmodernidad se desvinculó de las ideas universales asociadas a la autoría y tras esta experiencia podríamos decir que las tecnologías de la imagen han pasado a reinterpretar la autoría como un elemento abierto e hipertextual que aborda el reciclaje y la apropiación como una actividad ecológica ${ }^{13}$ tal y como nos cuenta Joan Fontcuberta.

Según Juan Martín Prada ${ }^{14}$, como contraste a las estrategias de reubicación y descontextualización de la posmodernidad, el medio digital va a pasar a transformar dentro de una integración y fusión de lo apropiado. Para ello va a usar conceptos provenientes de otros medios como remix, sample, mash-up o remake. Todos nos hablan del uso de elementos de otras piezas, la mezcla y transformación en una versión alternativa.

Estas prácticas están asociadas a la provisionalidad y temporalidad de materiales recogidos de la red tal y como el poeta estadounidense Kenneth Goldmisth afirma ${ }^{15}$, los cuales son almacenados, moldeados y descartados con una rapidez proporcional a la de los flujos de información. Goldsmith defiende el plagiarismo como una estrategia creativa, creando dentro de sus clases en la Universidad de Pensilvania un completo decálogo de cómo perder el tiempo dentro de la red. Ante la avalancha de material que generamos diariamente Goldsmisth aboga por la apropiación literal como acto creativo.

Analizando obras recientes de diferentes artistas contemporáneos podemos ver como estas prácticas se han insertado plenamente dentro del sistema del arte. Vivimos en un mundo donde el imaginario es producido por imágenes de nuestra vida diaria. Estas imágenes son distribuidas como un producto de la industria cultural. Dina Kelberman en su proyecto en curso I'm Google $e^{16}$ colecciona lotes de imágenes de Google Image Search y videos de Youtube que se relacionan en cuanto a composición, color o temática. Crea una instalación interactiva donde las imágenes se relacionan con otras imágenes, pudiendo mover mediante un trackpad la cascada sin fin formada por el blog de Tumblr que sirve como alojamiento al proyecto. Según la artista este es el resultado natural del hábito obsesivo de pasar horas buscando dentro del buscador de imágenes de Google, coleccionándolas y ordenándolas por tema. Como la propia artista indica este blog es el resultado visual de este fenómeno. Aquí el artista se comporta como un coleccionista que usa el imaginario generado por la propia red para conformar su obra. Esta pasa a ser el resultado del acto cotidiano de recorrer la red.

\footnotetext{
${ }^{9}$ Walter, Benjamin, El libro de los pasajes, Akal, Madrid, 2005.

${ }^{10}$ Mitchell, William J. T., Teoría de la Imagen: ensayos sobre la representación verbal y visual, Akal, Madrid, 2009, pag. 214.

11 Jameson, Fredric. El posmodernismo o la lógica cultural del capitalismo avanzado, Paidos, Barcelona, 1991, pag. 35.

${ }^{12}$ Martín Prada, Juan, La Apropiación Posmoderna: Arte, práctica apropiacionista y Teoría de la Posmodernidad, Editorial Fundamentos, Madrid, 2001, pag. 49.

${ }_{13}^{13}$ Fontcuberta, Joan, La cámara de Pandora, Gustavo Gili, Barcelona, 2011.

${ }_{15}^{14}$ Martín Prada, Juan, Prácticas Artísticas en Internet en la Época de las Redes Sociales, Akal, Madrid, 2012, pag. 187.

${ }^{15}$ Goldsmith, Kenneth, Uncreative Writing, Columbia University Press, Nueva York, 2011, pag. 218.

${ }^{16}$ Kelberman, Dina, I'm Google, 2011, [Consulta 23 de Enero de 2017] disponible en <http://dinakelberman.tumblr.com>
} 


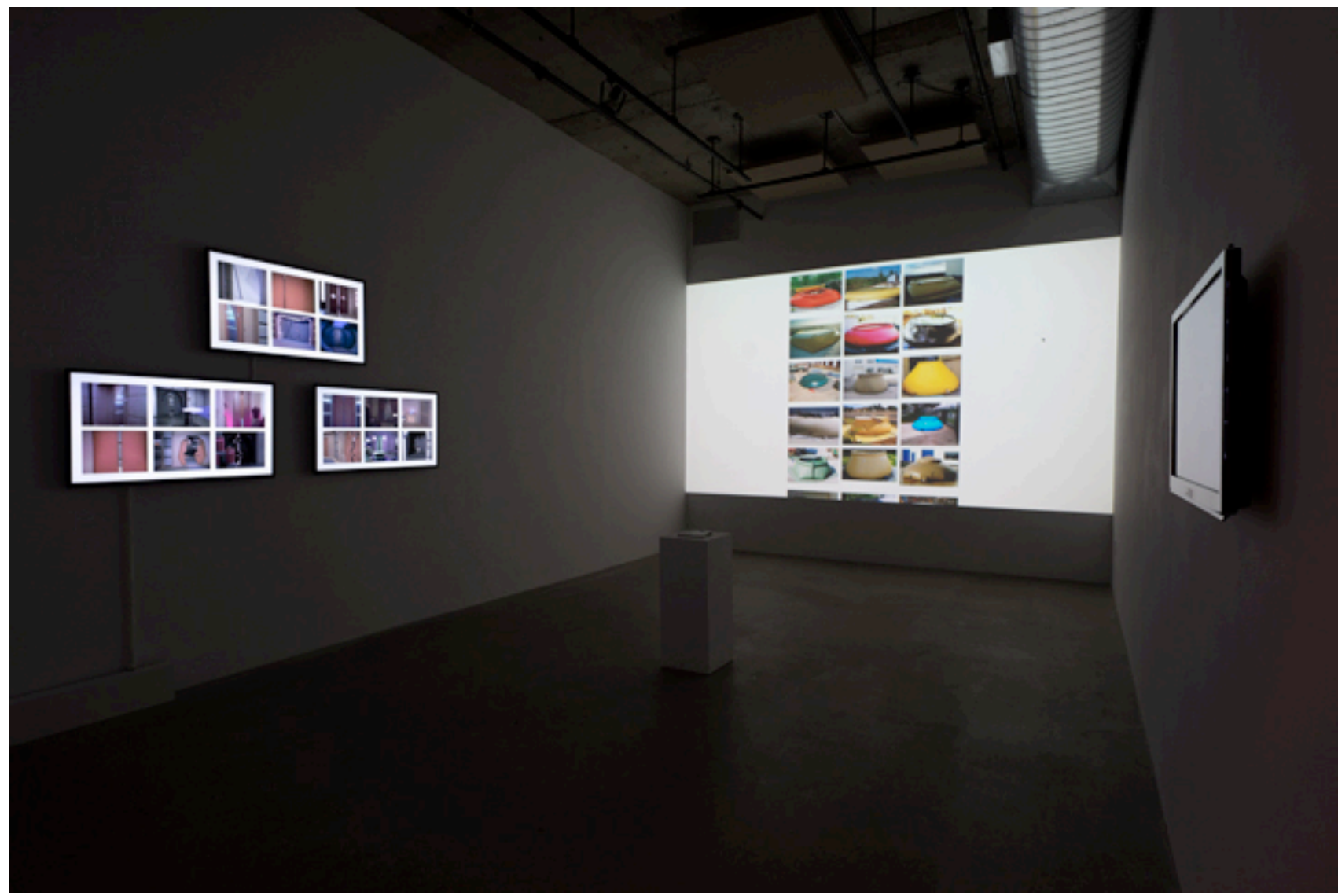

I'm Google de Dina Kelberman, Centre Clark, Montreal, 2011.

Va a ser muy importante la viralización y mutación de diferentes materiales que son transformados y reciclados por diferentes comunidades virtuales, generando nuevos significados e interpretaciones. El paradigma de esta replicación constante lo encontramos en los memes de Internet, los cuales, mediante diferentes medios de construcción multimedia, describen una idea, concepto o expresión que adquiere una difusión masiva gracias a foros, image boards o redes sociales. Los memes tienden a ser reinterpretados, modificados, parodiados y en definitiva resignificados por los propios usuarios. Adquieren un rol de interfaz comunicativo que alienta su propagación mediante la interacción social, ya que en muchos casos comunican una determinada idea, opinión o concepto. La artista española Cristina Garrido en su proyecto They are these or the may be others ${ }^{17}$, decide realizar una investigación en varias plataformas de arte contemporáneo en Internet, galerías y redes sociales, desarrollando un archivo de 2500 imágenes de instalaciones exhibidas durante 2011. Tras esta recopilación género 21 categorías diferentes de acuerdo a la repetición de diferentes elementos dentro de las obras. En base a esta investigación desarrolló 21 imágenes modificadas, que sintetizan cada una de estas 21 tipologías. Estas fotografías son representadas como memes de Internet añadiéndoles un texto pintado que describe la categoría de cada imagen. Aquí la artista juega con la idea de la copia intelectual de la propia obra y la repetición que, al igual que Internet, el propio sistema del arte genera. Poniendo el acento en el origen de las mismas nos habla sobre la legitimación que el artista persigue mediante su obra y por lo tanto la razón fundamental para este ejercicio de mimetización. Por otro lado, al realizar una fotografía original de cada tipología e intervenirla mediante pintura genera una reflexión sobre el valor de la obra que escapa a la voluntad del propio artista.

\footnotetext{
${ }^{17}$ Garrido Cristina, They are these or the may be others, 2014 [Consulta 23 de Enero de 2017] disponible en <http://www.cristinagarrido.com/They-are-these-or-the-may-be-others>
} 


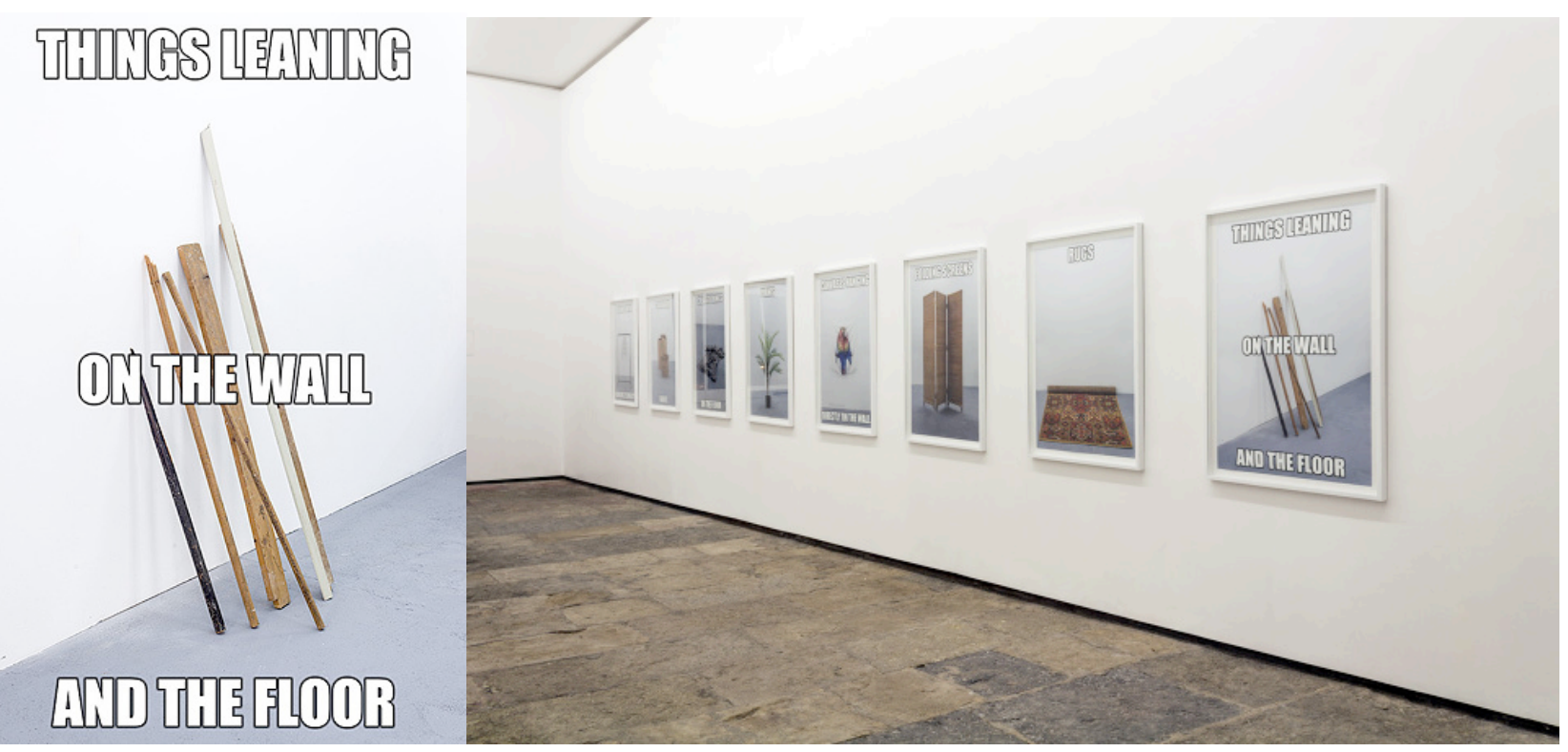

They are these or the may be others, Cristina Garrido, 2014.

El interés del artista canadiense Jon Rafman por la producción mediática de subculturas y comunidades en línea como 4 chan ${ }^{18}$ o Second Life ${ }^{19}$ le ha llevado a explorar las posibilidades artísticas del estudio antropológico de estos espacios. En su obra Mainsqueeze de 2014, Rafman se apropia de "found fottage" o material ya existente que ha sido realizado, distribuido y reciclado por estas comunidades. Mediante esta obra de video profundiza en los aspectos más perturbadores del material producido por estas comunidades anónimas. Lo reubica mediante las propias posibilidades que la edición ofrece para sumergirnos en este submundo digital. Como él mismo confiesa, está interesado en la aplicación social que le damos a la tecnología y lo que los usuarios crean mediante estas tecnologías sin ninguna intencionalidad artística en base a su propia pasión por crear. Rafman usa esta creatividad amateur de las subculturas de Internet como una fuente de material para su práctica artística, actuando como un antropólogo visual amateur y "flâneur" que se nutre de los símbolos y lenguajes de estos entornos virtuales. Como el propio artista nos cuenta:

"Mainsqueeze expresa una condición moral o emociones sin hacer ningún juicio moral. Gravito entre comunidades como 4chan por qué los veo como una mezcla irresistible entre atracción y repulsión. Esta ambivalencia esta reflejada en el momento cultural actual". ${ }^{20}$

\footnotetext{
${ }^{18}$ El tablón de imágenes 4chan creado en 2003 se caracteriza por el anonimato de sus usuarios y por no guardar registro de la actividad de los mismos, ya que esta queda eliminada a los pocos días de ser posteada. Se opone por tanto a los modelos de redes sociales y identidad persistente que la Web 2.0 ha extendido y apuesta por identidades fluidas, tal y como su propio creador Christopher Poole ha manifestado en más de una ocasión. Es por ello que fue el germen de comunidades como Anonymous famosa por sus acciones activistas contra determinados gobiernos y corporaciones, así como de la propagación de infinidad de memes y media pranks.

${ }^{19}$ Second Life es un metaverso creado en 2003. Los usuarios pueden establecer relaciones sociales y económicas, o explorar este basto universo. Tiene su propia moneda llamada Linden Dólar intercambiable por dinero real lo que ha generado toda una economía virtual dentro de este espacio.

${ }^{20}$ Quaranta, Domenico, dismagazine.com, [Consulta 23 de Enero de 2017] disponible en <http://dismagazine.com/dystopia/65372/jonrafman-mainsqueeze>
} 
Préstamos, apropiaciones y plagios. Meditaciones sobre los arquetipos de la web 2.0

III CONGRESO INTERNACIONAL DE INVESTIGACIÓN EN ARTES VISUALES :: ANIAV 2017 :: GLOCAL [codificar, mediar, transformar, vivir] http://dx.doi.org/10.4995/ANIAV.2017.5737

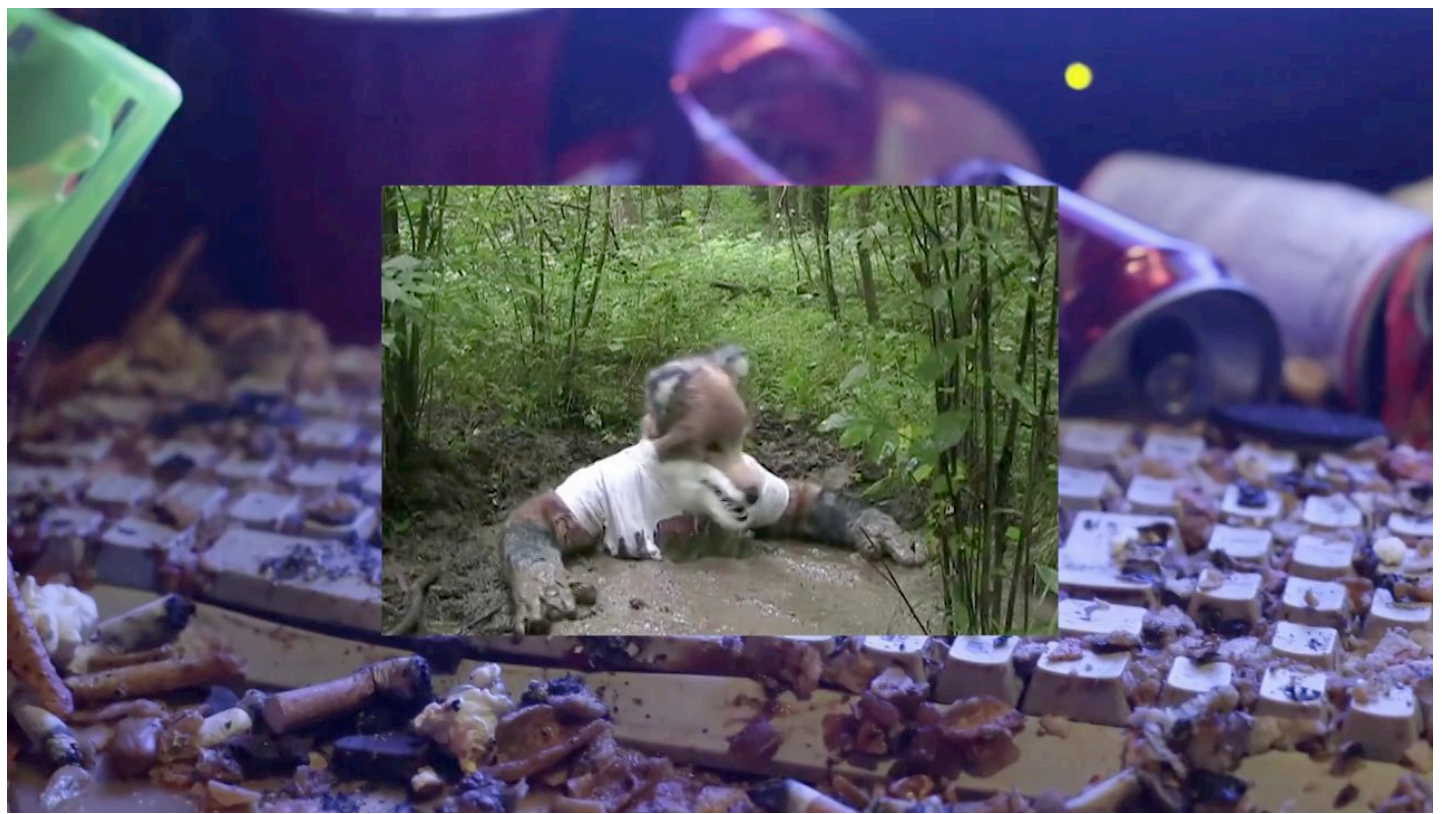

Mainsqueeze, Jon Rafman, 2014.

Por último podríamos reflexionar sobre la verdadera naturaleza física de toda esta sobreproducción mediática que existe de manera intangible, la obra Horizon del artista francés Gregory Chatonsky realizada en 2016 es una reflexión sobre la inmaterialidad del contenido que compone la web dentro de lo que ha venido a denominarse como la nube. Este término responde al paradigma mediante el cual la información que producimos o las aplicaciones que usamos permanecen almacenadas permanentemente en los servidores de centros de datos. Aquí Chatonsky nos muestra la verdadera naturaleza material de los datos de Internet, y cómo la inmensa producción de los medios masivos dentro de la red es almacenada. Para ello se apropia de imágenes encontradas en la web en las cuales podemos ver los pasillos de inmensos centros de datos. Usa estas imágenes para generar travellings infinitos en base a estas imágenes con perspectiva albertiana. Resulta irónico el propio uso de las imágenes de la red contenidas en la nube para representar el propio espacio donde son almacenadas.

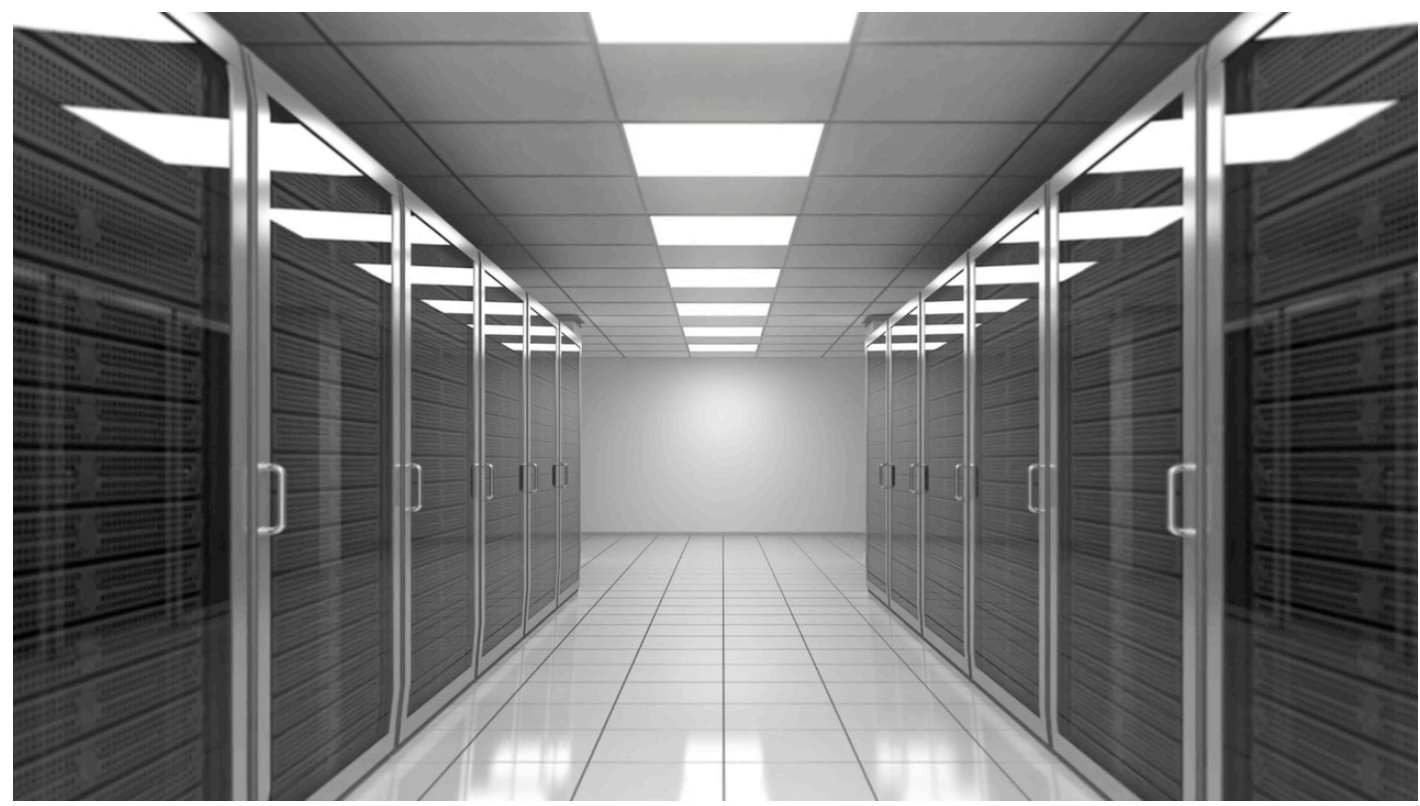

Horizon, Gregory Chatonsky, 2016. 


\section{CONCLUSIONES.}

Como hemos podido constatar el propio funcionamiento de la red delimita en gran medida el tipo de participación e interacción que realizamos, propiciando un determinado tipo de producción mediática que alimenta este mismo sistema. En cambio, podemos observar como esta conducción de nuestro comportamiento dentro de la red es difícil de detener y revertir, alimentando nosotros mismos los cuerpos de datos que generan tanto nuestra propia vigilancia online como el marketing desarrollado en base a nuestra actividad en la red. Podríamos decir que la creatividad amateur en gran medida se genera ajena a estos hechos cediendo parte de su privacidad por la contraprestación de un servicio gratuito. La obra de Christophe Bruno The Google Adwords Happening ${ }^{21}$, es una exploración sobre los aspectos económicos implícitos en las búsquedas que realizamos diariamente en Google. Bruno comenzó una campaña publicitaria, que podríamos considerar un happening en el servicio de anuncios de Google llamado Google Adwords ${ }^{22}$. Se vale de esta herramienta de publicidad contextual para insertar poemas en la web, pervirtiendo la intencionalidad comercial de esta. Precisamente en la reutilización crítica de herramientas y espacios es donde está la posibilidad de subvertir los productos de la cultura visual de masas, rompiendo esta relación entre tecnología, economía y sociedad.

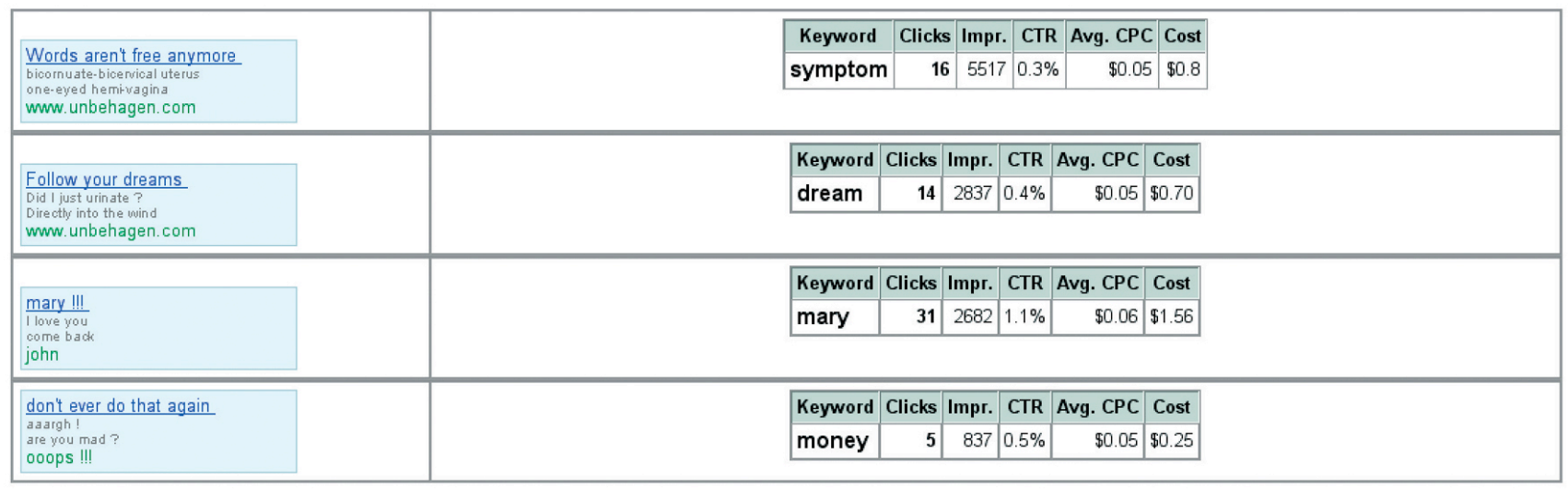

The Google Adwords Happening, Christophe Bruno, 2002.

Por otro lado la apropiación y modificación de material proveniente de esta cultura, se presenta como una manera de reinterpretar y generar nuevos contenidos desde el propio punto de vista del usuario. La creatividad amateur es pues un elemento indispensable para generar una reinterpretación o traducción cultural que también puede dar origen a diferentes políticas por parte de las compañías más representativas de la Web 2.0. Es aquí donde las comunidades virtuales tienen un papel importante a la hora de generar su propia cultura por si mismas, como hemos visto en la obra de Jon Rafman. Buscamos una individualidad que Cristina Garrido cuestiona podamos alcanzar dentro del sistema de la Web 2.0. Pese a los intentos de esta por identificarnos constantemente, solo nos hace más simples de lo que realmente somos. Nuestra cultura visual debe de dejar de ser tratada como un producto de la industria cultural, para pasar a ser el resultado de la interacción de los usuarios con un medio que debe de ser construido por ellos mismos. Estamos en un momento en el cual los espacios construidos y gobernados por los propios usuarios se han convertido en una excepción. La exigencia del uso de una identidad permanente ha hecho del anonimato, las identidades fluidas y la autorregulación, y por consiguiente de la libre expresión a través de estas, algo valioso y difícilmente sustentable. Ante esta perdida de opciones debemos cuestionar los arquetipos conceptuales e ideológicos de los medios de masas en los cuales nos desenvolvemos. Es aquí donde la práctica artística puede mediante la interacción con otras disciplinas generar una conciencia sobre la manera en la cual estas tecnologías estrechamente conectadas con nuestra vida diaria nos moldean de acuerdo al productivismo mediático.

\footnotetext{
${ }^{21}$ Chritophe, Bruno, The Google Adwords Happening, 2002, [Consulta 23 de Enero de 2017] disponible en $<$ http://www.iterature.com/adwords>

${ }^{22}$ Esta obra alcanzó una duración de 24 hora a comienzos de Abril de 2002. Para ello comenzó a realizar anuncios relacionados con determinadas palabras clave, mediante las cuales desarrollaba un texto en forma de poema, de manera que el espectador se encuentra con un poema en forma de anuncio clasificado que esta relacionado con esta palabra clave que el busca.
} 


\section{FUENTES REFERENCIALES.}

Castells, Manuel. La Galaxia Internet, Areté, Barcelona, 2001.

Fontcuberta, Joan, La cámara de Pandora, Gustavo Gili, Barcelona, 2011.

Garrido Cristina, They are these or the may be others, 2014 [Consulta 23 de Enero de 2017] disponible en < http://www.cristinagarrido.com/They-are-these-or-the-may-be-others >

Goldsmith, Kenneth, Uncreative Writing, Columbia University Press, Nueva York, 2011.

Himanen, Pekka, La ética hacker y el espíritu de la era de la información, Editorial Destino, 2002.

Jameson, Fredric. El posmodernismo o la lógica cultural del capitalismo avanzado, Paidos, Buenos Aires 1991.

Jansson, André, Christensen, Miyase, Media, surveillance and identity, Peter Lang, Nueva York, 2014.

Kelberman, Dina, I'm Google, 2011, [Consulta 23 de Enero de 2017] disponible en < http://dinakelberman.tumblr.com/ >

Martín Prada, Juan, La Apropiación Posmoderna: Arte, práctica apropiacionista y Teoría de la Posmodernidad, Editorial Fundamentos, Madrid, 2001.

Martín Prada, Juan, Prácticas Artísticas en Internet en la Época de las Redes Sociales, Akal, Madrid, 2012.

McLuhan, Marshall, Understanding Media, Mit Press, Cambridge, 1994.

Mitchell, William J. T., Teoría de la Imagen: ensayos sobre la representación verbal y visual, Akal, Madrid, 2009.

O’Reilly, Tim, What Is Web 2.0. Design Patterns and Business Models for the Next Generation of Software, 2005 [Consulta 23 de Enero de 2017] disponible en <http://www.oreilly.com/pub/a/web2/archive/what-is-web-20.html>

Quaranta, Domenico, dismagazine.com, [Consulta 23 de Enero de 2017] disponible en <http://dismagazine.com/dystopia/65372/jonrafman-mainsqueeze/>

Walter, Benjamin, El libro de los pasajes, Akal, Madrid, 2005. 